\title{
Highly-efficient RuNi single-atom alloy catalysts toward chemoselective hydrogenation of nitroarenes
}

\section{Wei Liu}

Beijing University of Chemical Technology

\section{Yusen Yang}

Beijing University of Chemical Technology

\section{Haisong Feng}

Beijing University of Chemical Technology

\section{Yiming Niu}

Institute of Metal Research, Chinese Academy of Sciences https://orcid.org/0000-0001-9744-2339

\section{Lei Wang}

Beijing University of Chemical Technology

\section{Pan Yin}

Beijing University of Chemical Technology

\section{Song Hong}

Beijing University of Chemical Technology https://orcid.org/0000-0002-8532-3348

\section{Bingsen Zhang}

Institute of Metal Research, Chinese Academy of Sciences https://orcid.org/0000-0002-2607-2999

\section{Xin Zhang}

Beijing University of Chemical Technology https://orcid.org/0000-0003-3559-2096

Min Wei ( $\nabla$ weimin@mail.buct.edu.cn )

Beijing University of Chemical Technology https://orcid.org/0000-0001-5257-790X

\section{Article}

Keywords: RuNi single atom alloy, synergistic catalysis, electron transfer

Posted Date: September 10th, 2021

DOl: https://doi.org/10.21203/rs.3.rs-878026/v1

License: (a) (i) This work is licensed under a Creative Commons Attribution 4.0 International License. Read Full License 
Version of Record: A version of this preprint was published at Nature Communications on June 8th, 2022. See the published version at https://doi.org/10.1038/s41467-022-30536-9. 


\section{Abstract}

The design and exploitation of high-performance catalysts as well as understanding the structureproperty correlation have gained considerable attention in selective hydrogenation reactions, but remain a huge challenge. Herein, we report a RuNi single atom alloy (SAA) in which Ru single atoms are anchored onto Ni nanoparticle surface via Ru-Ni coordination accompanied with electron transfer from subsurface $\mathrm{Ni}$ to $\mathrm{Ru}$. The optimal catalyst $0.4 \%$ RuNi SAA exhibits simultaneously improved activity (TOF value: $4293 \mathrm{~h}^{-1}$ ) and chemoselectivity toward selective hydrogenation of 4-nitrostyrene to 4aminostyrene (yield: $>99 \%$ ), which is, to the best of our knowledge, the highest level compared with reported heterogeneous catalysts. In situ experimental researches based on XAFS, FT-IR measurements and theoretical calculations reveal that the $\mathrm{Ru}-\mathrm{Ni}$ interfacial sites as intrinsic active centers facilitate the preferential cleavage of $\mathrm{N}-\mathrm{O}$ bond in nitro group with a decreased energy barrier by $0.35 \mathrm{eV}$. In addition, the Ru-Ni synergistic catalysis promotes the formation of intermediates $\left(\mathrm{C}_{8} \mathrm{H}_{7} \mathrm{NO}^{*}\right.$ and $\left.\mathrm{C}_{8} \mathrm{H}_{7} \mathrm{NOH}^{*}\right)$ and accelerates the rate-determining step (hydrogenation of $\mathrm{C}_{8} \mathrm{H}_{7} \mathrm{NOH}^{*}$ ), resulting in the extraordinary activity and chemoselectivity toward nitroarenes hydrogenation.

\section{Introduction}

Functionalized aromatic amines, as the vital building blocks of fine chemicals, have crucial applications in industry for the production of pharmaceuticals, agrochemicals, pigments, and polymers ${ }^{1-3}$. Catalytic hydrogenation of readily available nitroarenes over heterogeneous catalysts is an environmentally benign and recyclable approach to the synthesis of value-added amines, which have attracted considerable attention ${ }^{4-7}$. However, the chemoselective reduction of $-\mathrm{NO}_{2}$ group while reserving the other reducible groups (e.g., alkenes, alkynes, halogen, or ketones) is a highly desirable yet rather rough task ${ }^{8-11}$. Therefore, it is of great necessity to rationally exploit heterogeneous catalysts to exclusively reduce the $-\mathrm{NO}_{2}$ group without affecting the other reducible bonds ${ }^{12-14}$. Many non-precious metal catalysts have been explored to catalyze the nitroarenes hydrogenation, but the rigorous reaction conditions hinder their comprehensive applications ${ }^{15,16}$. Although precious metal catalysts (e.g., $\mathrm{Ru}^{17}, \mathrm{Pt}^{18-20}$, or $\mathrm{Pd}^{21-23}$ ) are active under mild reaction conditions, they generally suffer from high cost, dissatisfactory selectivity and low atomic utilization. Hence, how to acquire highly active and chemoselective catalysts via rational design and regulation on fine structure remains a big challenge ${ }^{24-26}$.

Single atom alloy (SAA) catalysts, with their maximized noble metal utilization efficiency, specific geometric and electronic structure, provide unique active centers and result in outstanding catalytic properties that breaks the intrinsic linear scaling relationships ${ }^{27-31}$. The doped single atoms and host metal atoms in SAA can serve as dual-active sites which promote the activation of multiple substrates, or enable different elementary reaction steps occurring at different sites ${ }^{32-34}$. In addition, the heterometal combinations between isolated doped metal atoms and host metal may give rise to a special synergistic effect, although the understanding of this synergy of the two sets of metal sites at atomic scale still remain controversial ${ }^{35-38}$. As for the hydrogenation reaction of functionalize nitroarenes, the electronic 
and geometric structure of the active sites should be engineered to accelerate the exclusive activation of nitro-group. The electron-deficient nitro group tends to preferentially adsorb on the nucleophilic site on the surface of catalyst; whereas in the subsequent hydrogenation route, the cooperative catalysis of adjacent active center would play a vital role in governing the reactivity and chemoselectivity ${ }^{4,25}$. This evokes us to explore SAA catalyst as a promising candidate to improve catalytic performance toward chemoselective hydrogenation of nitroarenes, and further reveal the relationship between active site structure and catalytic property at atomic scale.

Herein, a RuNi single atom alloy catalyst was prepared based on a two-step synthesis method including a structural topological transformation of layered double hydroxides (LDHs) followed by a galvanic replacement treatment. The RuNi SAA exhibits extraordinary catalytic performance for chemoselective hydrogenation of 4-nitrostyrene to 4-aminostyrene (yield $>99 \%$ ), and the turnover frequency (TOF) value reaches up to $\sim 4300 \mathrm{~mol} \cdot \mathrm{mol}_{\mathrm{Ru}}{ }^{-1} \cdot \mathrm{h}^{-1}$, which stands at the highest level among heterogeneous catalysts ever reported under analogous reaction conditions. Electron microscopic and spectroscopic characterizations show that isolated Ru atoms are dispersed on Ni nanoparticles ( $~ 8 \mathrm{~nm})$ surface to form a stable $\mathrm{Ru}-\mathrm{Ni}$ coordination, which results in the negative $\mathrm{Ru}$ sites $\left(\mathrm{Ru}^{\delta-}\right)$ due to electron transfer from sub-surface Ni to Ru. In situ FT-IR, XAFS investigations and density functional theory (DFT) calculations confirm that Ru-Ni interfacial sites as intrinsic active centers facilitate the activation adsorption of nitro-group via both $\mathrm{Ru}-\mathrm{O}$ and $\mathrm{Ni}-\mathrm{O}$ bonds with a lower energy barrier $(0.43 \mathrm{eV})$, in contrast to monometallic $\mathrm{Ni}$ catalyst $(0.78 \mathrm{eV})$. Moreover, hydrogen undergoes dissociation on adjacent $\mathrm{Ni}$ sites, followed by the hydrogenation of intermediates $\left(\mathrm{C}_{8} \mathrm{H}_{7} \mathrm{NO}^{*}\right.$ and $\left.\mathrm{C}_{8} \mathrm{H}_{7} \mathrm{NOH}^{\star}\right)$ on the $\mathrm{Ru}^{\delta^{-}}$sites. This hostdopant synergistic effect in RuNi SAA catalyst results in outstanding activity and selectivity toward nitroarenes hydrogenation, which can be extended to other rare precious metal catalysts used in structure sensitive reactions.

\section{Results And Discussion}

Synthesis and characterization of RuNi bimetallic catalysts. A monometallic Ni supported on amorphous $\mathrm{Al}_{2} \mathrm{O}_{3}$ substrate was prepared based on structural topotactic transformation of layered double hydroxides (LDHs) precursors. Afterwards, a set of $\mathrm{RuNi} / \mathrm{Al}_{2} \mathrm{O}_{3}$ bimetallic samples with various $\mathrm{Ru}$ loading (0.1-2 $w t . \%)$ were precisely synthesized by a galvanic replacement method to deposit Ru atoms onto the surface of Ni nanoparticles (NPs) (Fig. 1a). Inductively coupled plasma atomic emission spectroscopy (ICP-AES) measurement explicitly gives the element composition of Ru and $\mathrm{Ni}$ in these samples (Supplementary Table 1), which is close to the theoretical loading of the feed. SEM images (Supplementary Fig. 1) and BET results (Supplementary Fig. 2-9, Supplementary Table 1) clearly reveal that the morphology structure and specific surface area of $\mathrm{RuNi} / \mathrm{Al}_{2} \mathrm{O}_{3}$ samples do not show obvious change during galvanic replacement process. The XRD patterns (Fig. 1b) show series of characteristic reflections at $2 \theta 44.3^{\circ}$, $51.6^{\circ}$, and $76.1^{\circ}$, indexed to the (111), (200), and (220) of a typical Ni (JCPDS 048-1548) phase. It is noted that the RuNi samples do not display metallic or oxidic Ru reflection, implying a high dispersion of Ru species. Transmission electron microscopy (TEM) measurements of monometallic Ni and RuNi 
samples (Fig. 1c1-c8) show that Ni nanoparticles are well dispersed and anchored onto the amorphous $\mathrm{Al}_{2} \mathrm{O}_{3}$ support with a close particle size (7.7-8.3 nm). HRTEM images (Fig. 1d1-d8) display a uniform lattice spacing of $\sim 0.203 \mathrm{~nm}$ in both $\mathrm{Ni}$ and RuNi samples, corresponding to $\mathrm{Ni}$ (111) plane; yet the lattice fringes of Ru species are absent. This indicates that the Ru atoms are highly dispersed on the surface of samples, without influence on the lattice constants of $\mathrm{Ni}$.

Catalytic behaviour for chemoselective hydrogenation of 4-nitrostyrene. The catalytic performance of RuNi samples were explored toward chemoselective hydrogenation of 4-nitrostyrene (4-NS) to 4aminostyrene (4-AS). As shown in Fig. 2a, the pristine Ni catalyst gives an extremely low catalytic activity with $7.1 \%$ 4-NS conversion after $3 \mathrm{~h}$, whereas $100 \%$ conversion is achieved in the presence of monometallic Ru catalyst under the same conditions. In contrast to monometallic samples, all the RuNi catalysts show significantly enhanced hydrogenation activity (conversion: $~ 100 \% ; 3 \mathrm{~h}$ ), and the reaction rate is positively correlated with Ru content. This implies that the Ru species play a crucial role during the hydrogenation process. Interestingly, the product selectivity (Fig. 2b) is significantly diverse over various catalysts. For pristine Ni catalyst with a rather low activity, 4-nitroethylbenzene (4-NE) is the main product (selectivity: $83.6 \%$ ) and the selectivity of $4-A S$ is $11.3 \%$. In the case of monometallic $\mathrm{Ru}$, the $\mathrm{C}=\mathrm{C}$ bond in 4-NS is peculiarly prone to undergo hydrogenation than $-\mathrm{NO}_{2}$, resulting in the formation of 4nitroethylbenzene (4-NE) or 4-aminoethylbenzene (4-AE); yet the selectivity of 4-AS is merely $15.7 \%$. Surprisingly, RuNi catalysts with relatively low Ru loading (0.1-0.4 wt.\%) exhibit an excellent selectivity (> $99 \%$ ) toward 4-aminostyrene (4-AS), indicating it is exclusively chemoselective for $-\mathrm{NO}_{2}$ rather than ethenyl. When Ru content is larger than $0.6 \mathrm{wt} . \%$, the selectivity to 4-AS declines sharply whilst that of 4$\mathrm{AE}$ augments instead, along with the increase of Ru loading. For the 2 wt.\% RuNi catalyst, both nitro and ethenyl are highly hydrogenated with the selectivity toward 4-AE up to $98 \%$. In addition, the turnover frequency (TOF) of RuNi catalysts was calculated for 4-nitrostyrene hydrogenation based on Ru sites, to further reveal the intrinsic catalytic activity (Fig. 2c). With the increase of Ru loading from $0.1 \mathrm{wt} \%$ to 0.4 $w t \%$, the RuNi catalysts exhibit an almost constant TOF value (4271-4293 $\left.\mathrm{h}^{-1}\right)$, indicating that the Ru species is located as atomic dispersion (might form RuNi SAA) and serves as the main active sites. However, the TOF value decreases significantly with a further increase of Ru loading (within 0.6-2 wt.\%), which implies a change of intrinsic active site structure (from atomic dispersion to Ru nanoclusters). Moreover, the TOF of $0.4 w t$. RuNi (SAA) catalyst, to the best of our knowledge, stands at the highest level among metal catalysts reported previously under similar reaction conditions (Supplementary Table 2), which further demonstrates RuNi single atom alloy affords superior catalytic performance. Supplementary Fig. 10 shows catalytic performance of $0.4 w t . \%$ RuNi (SAA) catalyst at various $\mathrm{H}_{2}$ pressure and temperature, from which $1 \mathrm{MPa}$ of $\mathrm{H}_{2}$ pressure and $60^{\circ} \mathrm{C}$ of reaction temperature are adopted as the optimal reaction parameters. The reusability of $0.4 w t . \%$ RuNi sample was further evaluated (Fig. 2d), and no significant shrink in both activity and yield was observed within five successive recycles. The XRD pattern and TEM images (Supplementary Fig. 11-12) of the used $0.4 w t . \%$ RuNi catalyst after 5 cycles do not show obvious change in crystal structure, indicating a high stability in the selective hydrogenation reaction. In addition, the $0.4 w t . \%$ RuNi (SAA) catalyst also achieved excellent 
amines yield toward the chemoselective hydrogenation of other nitroarenes contained halogen, aldehyde and hydroxyl group (Supplementary Table 3), which demonstrates its good applicability.

To further study the remarkable chemoselectivity difference, the hydrogenation of styrene and nitrobenzene mixture (1:1) was also performed in the presence of monometallic Ni, Ru, $0.4 w t . \%$ RuNi and 2 wt.\% RuNi catalysts, respectively (Supplementary Fig. 13). As shown in Fig. $2 \mathrm{e}$ and $2 \mathrm{f}$, the curve of In $\left(\mathrm{C}_{0} / \mathrm{C}\right)$ as a function of reaction time give a straight line starting with the origin point, indicating a pseudo first-order reaction with respect to both nitrobenzene and styrene. Monometallic Ni catalyst shows extremely low hydrogenation rate constant toward both nitrobenzene $\left(0.03 \mathrm{~h}^{-1}\right)$ and styrene $\left(0.05 \mathrm{~h}^{-1}\right)$. Notably, a preferential styrene hydrogenation activity (rate constant: $0.89 \mathrm{~h}^{-1}$ ) is achieved over monometallic Ru catalyst, which is greatly larger than nitrobenzene hydrogenation (rate constant: 0.18 $\mathrm{h}^{-1}$ ). In the case of $0.4 w t$.\% RuNi (SAA) catalyst, nitrobenzene hydrogenation is more dynamically favorable than styrene hydrogenation (rate constant: $1.90 \mathrm{~h}^{-1} v s .0 .04 \mathrm{~h}^{-1}$ ), indicating a preferred hydrogenation of $-\mathrm{NO}_{2}$ group rather than $\mathrm{C}=\mathrm{C}$ bond. For $2 \mathrm{wt}$.\% RuNi catalysts, the rate constant of nitrobenzene hydrogenation $\left(1.65 \mathrm{~h}^{-1}\right)$ drops compared with that of 0.4 wt.\% RuNi (but remains higher than monometallic catalysts), while the hydrogenation rate of styrene increases sharply (rate constant: $\left.0.68 \mathrm{~h}^{-1}\right)$. This further implies a significantly promoted catalytic activity and chemoselectivity toward $-\mathrm{NO}_{2}$ group over RuNi SAA with the synergistic effect between $\mathrm{Ni}$ and $\mathrm{Ru}$.

Investigations on structure-selectivity correlations. Aberration-correction high-angle annular dark-field scanning transmission electron microscopy (AC-HAADF-STEM) imaging technique and energydispersive spectroscopy (EDS) elemental mapping were conducted to intuitively ascertain the dispersion state of Ru and Ni species. EDS elemental mapping of 0.4 wt.\% RuNi sample (Fig. 3a, b) illustrates a highly uniform dispersion of Ru on Ni nanoparticles rather than $\mathrm{Al}_{2} \mathrm{O}_{3}$ substrate; corresponding $\mathrm{AC}-$ HAADF-STEM image (Fig. 3c) shows that a number of atom-sized bright spots (highlighted by the blue arrows) attributed to individual Ru atoms are distributed on the surface of Ni NPs, without observation of Ru clusters or nanoparticles. Enlarged STEM image along with the intensity profile further verifies that Ru atoms are atomically dispersed on Ni NPs (Fig. 3d), demonstrating the formation of RuNi single atom alloy. For the $0.6 w t$.\% RuNi sample (Fig. 3e), both Ru single atoms and few Ru ensembles are observed on Ni NPs, suggesting a slight aggregation of Ru atoms due to the increase in loading. In the case of 2 $w t$ \% RuNi sample, a number of large Ru clusters are detected on Ni NPs in HAADF-STEM image (Fig. 3f) and EDS elemental mapping (Supplementary Fig. 14), indicating a considerable aggregation of Ru.

In situ DRIFTS spectra of $\mathrm{CO}$ adsorption (Fig. 4a) was performed to further explore structural details of $0.4 w t . \%, 0.6 w t . \%$ and $2 w t$. RuNi samples, in comparison with $\mathrm{Ni} / \mathrm{Al}_{2} \mathrm{O}_{3}$ and $\mathrm{Ru} / \mathrm{Al}_{2} \mathrm{O}_{3}$ samples. $\mathrm{CO}$ adsorption on $\mathrm{Ru} / \mathrm{Al}_{2} \mathrm{O}_{3}$ sample produces dominant peak at $2060 \mathrm{~cm}^{-1}$ and another broad peak at 1849 $\mathrm{cm}^{-1}$, which are assigned to linearly adsorbed $\mathrm{CO}$ at $\mathrm{Ru}$ and bridged-bonded $\mathrm{CO}$ at two contiguous $\mathrm{Ru}$ atoms, respectively ${ }^{39,40}$. For monometallic Ni sample, only a strong peak at $2057 \mathrm{~cm}^{-1}$ is observed, which is attributed to the linear $\mathrm{CO}$ on Ni site ${ }^{41,42}$. In the case of RuNi samples, in addition to the main peak at 
$2056 \mathrm{~cm}^{-1}$, an obvious shoulder peak centered at $\sim 2030 \mathrm{~cm}^{-1}$ is observed. By using Gaussian peak fitting method, the profiles of RuNi samples within $2000-2100 \mathrm{~cm}^{-1}$ are reasonably deconvoluted and fitted to two peaks including CO linear-type adsorption on Ni site $\left(2056 \mathrm{~cm}^{-1}\right)$ and Ru site (2031-2039 $\mathrm{cm}^{-1}$ ) (Fig. 4b). Interestingly, a remarkable red shift of the linear-bonded $\mathrm{CO}$ peak on Ru site occurs from $\mathrm{Ru} / \mathrm{Al}_{2} \mathrm{O}_{3}\left(2060 \mathrm{~cm}^{-1}\right)$ to RuNi samples $\left(2031-2039 \mathrm{~cm}^{-1}\right)$, and the red shift gradually became pronounced with the decrease in Ru content. This indicates an enhanced electronegativity of Ru species in RuNi samples owing to the electron transfer from Ni to Ru. Furthermore, for the $0.4 w t$.\% RuNi samples, no bridge adsorption peak is observed, implying that Ru species exists as isolated atoms (SAA) by Ni. In the case of $0.6 w t . \%$ RuNi and $2 w t$.\% RuNi samples, the appearance of bridge-bonded CO confirms the existence of Ru multimer or clusters, which accords well with the AC-HAADF-STEM results.

The normalized Ru K-edge in situ X-ray absorption near-edge structure (XANES) spectra were conducted to study the electronic structure of RuNi samples in contrast to Ru foil and $\mathrm{RuO}_{2}$ samples. As shown in Fig. $4 \mathrm{c}$, the intensity of white line shrinks gradually from $\mathrm{Ru} / \mathrm{Al}_{2} \mathrm{O}_{3}$ to RuNi samples along with the decrease of Ru loading. Simultaneously, the white line intensity of Ni K-edge XANES spectra shows a slight increase from pristine Ni to RuNi samples (Supplementary Fig. 15). This indicates the electron transfer from $\mathrm{Ni}$ atoms to $\mathrm{Ru}$ atoms which results in an enhanced electronegativity of $\mathrm{Ru}\left(\mathrm{Ru}^{\delta-}\right){ }^{43}$. The Bader charge analysis of RuNi SAA (111) surface reveals that isolated Ru atom carry negative charges from sub-surface Ni atoms (Supplementary Fig. 16), which is in accordance with the in situ DRIFTS and XANES spectra results. The Fourier transforms of the extended X-ray absorption fine spectrum (EXAFS) in the R space was performed to investigate the detailed coordination structure of Ru (Fig. $4 \mathrm{~d}$ ). The $0.4 w t . \%$ RuNi sample exhibits a sharp peak located at $\sim 2.1 \AA$, which is in the region between Ru- 0 shell $(1.5 \AA)$ and $\mathrm{Ru}-\mathrm{Ru}$ shell $(2.4 \AA)$ and can be assigned to the Ru-Ni coordination ${ }^{44,45}$. The EXAFS data-fitting results (Supplementary Table 4, Supplementary Fig. 17-20) manifest that the coordination number (CN) of $\mathrm{Ru}-\mathrm{Ni}$ path is 5.4 , while the $\mathrm{Ru}-\mathrm{Ru}$ and $\mathrm{Ru}-\mathrm{O}$ coordination are absent in 0.4 wt.\% RuNi sample. This verifies that predominant $\mathrm{Ru}$ atoms are atomically dispersed and surrounded by $\mathrm{Ni}$ to form single atom alloy. Notably, the peak intensity of Ru-Ru coordination ( $2.4 \AA$ ) arises in $0.6 w t$.\% RuNi sample and enhances in $2 w t$.\% RuNi sample. Exactly, the EXAFS curve fittings reveal that the Ru-Ru coordination number distinctly increases from 0 (0.4 wt.\% RuNi) to 2.2 (0.6 wt.\% RuNi) and further to 6.7 (2 wt.\% RuNi), respectively, indicating the Ru atoms aggregate gradually upon increasing Ru loading. The $k^{2}$-weighted wavelet transform (WT) for the Ru K-edge XAFS signals were further employed to study coordination environment of Ru species. As shown in Fig. 4e, the lobe of Ru foil at 2.3 $\AA, 9.7 \AA^{-1}$ is ascribed to $R u-R u$ contribution. The absence of lobes at $k=9.7 \AA^{-1}$ and $5.3 \AA^{-1}$ in $0.4 w t . \%$ RuNi sample (Fig. 4f) excludes the central $\mathrm{Ru}$ bonds to $\mathrm{Ru}$ atom and $\mathrm{O}$ atom (Fig. $4 \mathrm{~g}$ ); meanwhile, a new lobe attributed to $\mathrm{Ru}-\mathrm{Ni}$ contribution is observed at $2.1 \AA, 7.1 \AA^{-1}$, demonstrating the formation of SAA. Moreover, Ni K-edge EXAFS spectrum of different samples does not show significant differences (Supplementary Fig. 21), indicating that the coordination structure of $\mathrm{Ni}$ is less affected by the surface Ru atoms. In brief, the results of AC-HAADF-STEM, in situ CO-DRIFTS as well as in situ XAFS experiments substantiate the successful preparation of RuNi SAA catalyst, as well as the evolution of Ru species on Ni NPs from single 
atom to Ru multimers by increasing Ru loading. In addition, the HAADF-STEM image (Supplementary Fig. 22) and EXAFS spectrum (Supplementary Fig. 23) of the used RuNi SAA catalyst display that the dispersion state and coordination structure of Ru atoms do not show obvious change after 5 cycles, demonstrating a high stability of RuNi SAA catalyst.

Mechanism insight of hydrogenation of 4-NS on RuNi SAA. $\mathrm{H}_{2}$-TPD measurement was performed to explore dissociated adsorption of hydrogen on various catalysts, and the results showed that all these catalysts give strong $\mathrm{H}_{2}$ dissociation ability with desorption peaks at $\sim 100^{\circ} \mathrm{C}$ (Supplementary Fig. 24). DFT calculation was carried out to further study the adsorption and dissociation behavior of hydrogen on RuNi SAA in comparison with monometallic Ni (Supplementary Fig. 25). For RuNi SAA sample, $\mathrm{H}_{2}$ molecule preferentially undergoes chemical adsorption at the top site of Ru single atom with an adsorption energy of $-0.76 \mathrm{eV}$. Subsequently, the hydrogen dissociates into two $\mathrm{H}$ active atoms at $\mathrm{Ru}-\mathrm{Ni}$ hollow site of RuNi SAA overcoming an energy barrier of $0.02 \mathrm{eV}$. In addition to the Ru site, $\mathrm{H}_{2}$ molecule can also be chemically adsorbs on the top site of $\mathrm{Ni}$ atom adjacent to $\mathrm{Ru}$ (adsorption energy: $-0.38 \mathrm{eV}$ ), and then dissociates into two $\mathrm{H}$ atoms at $\mathrm{Ru}-\mathrm{Ni}$ and $\mathrm{Ni}-\mathrm{Ni}$ hollow sites with a barrier of $0.06 \mathrm{eV}$. In contrast, the adsorption energy and dissociation energy barrier of $\mathrm{H}_{2}$ molecule on $\mathrm{Ni}$ (111) surface are $-0.40 \mathrm{eV}$ and $0.09 \mathrm{eV}$, respectively. The extremely low energy barriers and subtle difference indicate that $\mathrm{H}_{2}$ is prone to dissociate on both Ni and RuNi SAA surface (either Ni site or Ru site), which is not the key factor influencing their catalytic performance.

The activation adsorption of specific functional group is of vital significant to selective hydrogenation of substrates. Hence, we conducted DFT calculations to investigate the possible adsorption configurations and active sites of 4-NS on RuNi SAA (111) surface, and the optimized results were shown in Supplementary Fig. 26. Clearly, the parallel configuration (Fig. 5a, Supplementary Fig. 26e), in which N atom is located at the Ru-Ni hollow site with two $\mathrm{O}$ atoms attaching on the Ru-Ni interface, displays the lowest level of adsorption energy $(-3.29 \mathrm{eV})$. This indicates a more thermodynamically favorable adsorption mode in comparison to vertical and other parallel configurations (Supplementary Fig. 26a-d). Moreover, after the adsorption of 4-NS on the RuNi SAA (111), the bond length of $\mathrm{N}-01\left(\mathrm{~L}_{(\mathrm{N}-\mathrm{O} 1)}\right)$ in nitrogroup is extended to $1.333 \AA$ (Fig. $5 \mathrm{a}$ ), which is significantly longer than that of gaseous 4-NS molecule (1.244 $\AA$ ) (Supplementary Fig. 27) and even exceeds the $L_{(N-01)}$ on Ni (111) (1.319 $\AA$ ). This suggests a prominently enhanced activation adsorption of $\mathrm{N}-01$ bond onto RuNi SAA surface, in comparison with the pristine $\mathrm{Ni}$ (111).

To further verify the adsorption behavior of 4-NS, in situ FT-IR measurements were performed over monometallic Ni, monometallic Ru, 0.4 wt.\% RuNi (SAA) and 2 wt.\% RuNi catalysts (Fig. 5b). The FT-IR spectra of gaseous 4-NS shows three characteristic peaks located at 1603, 1532 and $1356 \mathrm{~cm}^{-1}$, attributing to $v(\mathrm{C}=\mathrm{C}), v_{\mathrm{as}}\left(\mathrm{NO}_{2}\right)$ and $v_{\mathrm{s}}\left(\mathrm{NO}_{2}\right)$, respectively ${ }^{46-48}$. In the presence of monometallic $\mathrm{Ni}$, a redshift of all these three bands is observed: $v(\mathrm{C}=\mathrm{C})\left(1595 \mathrm{~cm}^{-1}\right), v_{\mathrm{as}}\left(\mathrm{NO}_{2}\right)\left(1520 \mathrm{~cm}^{-1}\right)$ and $v_{\mathrm{s}}\left(\mathrm{NO}_{2}\right)(1351$ $\mathrm{cm}^{-1}$ ), indicating both $\mathrm{C}=\mathrm{C}$ and $-\mathrm{NO}_{2}$ groups undergo chemisorption on the surface of $\mathrm{Ni}$ (most likely parallel adsorption configuration). For monometallic Ru sample, a more pronounced red-shift of these 
three bands is found $\left(1591,1514\right.$ and $1348 \mathrm{~cm}^{-1}$, respectively) relative to monometallic $\mathrm{Ni}$, indicating a slightly enhanced adsorption of nitro-group and $\mathrm{C}=\mathrm{C}$ bond on Ru. In the case of 0.4 wt.\% RuNi (SAA), the $v(C=C)$ band is centered at $1596 \mathrm{~cm}^{-1}$, rather close to monometallic $\mathrm{Ni}\left(1595 \mathrm{~cm}^{-1}\right)$, indicating vinyl tends to adsorb at the Ni sites of RuNi SAA. In addition, in striking contrast to the monometallic catalysts, the relative intensity of $v_{\mathrm{s}}\left(\mathrm{NO}_{2}\right)$ band $\left(1347 \mathrm{~cm}^{-1}\right)$ is significantly weaker than that of $v_{\text {as }}\left(\mathrm{NO}_{2}\right)(1512$ $\mathrm{cm}^{-1}$ ) on $0.4 w t . \%$ RuNi (SAA), which is attributed to the cleavage of $\mathrm{N}-\mathrm{O}$ bond in $-\mathrm{NO}_{2}$ to generate nitroso intermediate according to previous studies ${ }^{49,50}$. A similar phenomenon was also observed in 2 $w t . \%$ RuNi sample. The results above confirm that the synergy of bimetallic sites in RuNi SAA promotes the polarization and dissociation of nitro group, which accords well with the optimal adsorption configuration obtained by DFT calculations.

In situ XAFS spectroscopy was performed to investigate the dynamic evolution in electronic structure and coordination state of RuNi SAA during both 4-NS adsorption and catalytic reaction process. As shown in the Ru K-edge XANES spectrum (Fig. 5c), the absorption edge shifts remarkably to higher energy after adsorption of 4-NS on 0.4 wt.\% RuNi SAA, accompanied with an enhanced white line intensity, indicating the Ru species undergoes partial oxidation due to the electron transfer from Ru to 4-NS. Furthermore, the phase correction EXAFS Fourier-transform spectra (Fig. 5d) of 4-NS adsorbed RuNi SAA show distinctly increased signals at $\sim 1.7 \AA$ and $\sim 3.2 \AA$, which are ascribed to the formation of Ru-O coordination. After the introduction of $\mathrm{H}_{2}$ for $30 \mathrm{~min}$, both the XANES and EXAFS spectra of $0.4 w t$. \% RuNi SAA recover to their original state. These phenomena indicate that the nitro-group adsorbs on Ru site based on electronic interaction via Ru-O bond. As for the Ni-K edge in situ XAFS spectroscopy (Supplementary Fig. 28), no obvious change is observed, which is possibly due to the dilutive effect of $\mathrm{Ni}$ atoms in the bulk phase on the surface Ni species. The projected density of states (PDOS) of RuNi SAA (Fig. 5e) show that the unoccupied states of nitro group over Femi level widen in adsorption state and shift below the Femi level, which further manifests electron transfer from $d$-states of RuNi SAA to the unoccupied states in $-\mathrm{NO}_{2}$. Charge density difference (Supplementary Fig. 29) and Bader charge analysis (Supplementary Fig. 30) display that the integral electrons density of 4-NS is accumulated after its adsorption on RuNi SAA (111) surface. Moreover, compared with the vinyl group in 4-NS, the charge density of $-\mathrm{NO}_{2}$ enhances more significantly by virtue of the electron transfer from $\mathrm{Ru}-\mathrm{Ni}$ interface, indicating in the specific activation of the $\mathrm{N}-\mathrm{O}$ bond in nitro group.

In situ FT-IR was performed to monitor the catalytic reaction process of 4-NS hydrogenation on catalyst samples (Fig. 6). For pristine Ni catalyst (Fig. 6a), only a slight decrease in band density of nitro groups (1561 and $\left.1332 \mathrm{~cm}^{-1}\right)$ and $\mathrm{C}=\mathrm{C}\left(1595 \mathrm{~cm}^{-1}\right)$ was observed along with flowing $\mathrm{H}_{2}$ for $12 \mathrm{~min}$, indicating a rather weak activation for both $-\mathrm{NO}_{2}$ and $\mathrm{C}=\mathrm{C}$. In the presence of monometallic $\mathrm{Ru}(\mathrm{Fig} .6 \mathrm{~b})$, the $v(\mathrm{C}=$ C) band (at $\left.1591 \mathrm{~cm}^{-1}\right)$ shrinks rapidly within 0-12 min whist the bands of $v_{\mathrm{s}}\left(\mathrm{NO}_{2}\right)$ and $v_{\mathrm{as}}\left(\mathrm{NO}_{2}\right)$ decline very slowly. This manifests the preferential activation hydrogenation of vinyl-group, resulting in the formation of 4-nitroethylbenzene (4-NE). In the case of 0.4 wt.\% RuNi (SAA) (Fig. 6c), with the inflow of hydrogen, the band of $v_{\mathrm{s}}\left(\mathrm{NO}_{2}\right)\left(1347 \mathrm{~cm}^{-1}\right)$ disappears rapidly accompanied with a gradual recession of 
$v(\mathrm{~N}=0)$; whilst a new band centered at $1629 \mathrm{~cm}^{-1}$ ascribed to $\mathrm{N}-\mathrm{H}$ bending vibration is observed. Moreover, the band of $v(C=C)\left(1596 \mathrm{~cm}^{-1}\right)$ merely displays a rather slight decline after $12 \mathrm{~min}$. This dynamic variation verifies the polarization and hydrogenation of $-\mathrm{NO}_{2}$ to $-\mathrm{NH}_{3}$ over $0.4 w t$. $\% \mathrm{RuNi}(\mathrm{SAA})$, in accordance with the unique chemoselectivity toward 4-aminostyrene. For 2 wt.\% RuNi sample (Fig. 6d), in addition to the appearance of a new band attributed to $\delta(\mathrm{N}-\mathrm{H})$ at $1628 \mathrm{~cm}^{-1}$, the band of $v(\mathrm{C}=\mathrm{C})$ decreases and fades away preferentially compared with the bands of nitro group (1561 and $\left.1332 \mathrm{~cm}^{-1}\right)$. This indicates both $\mathrm{C}=\mathrm{C}$ and $-\mathrm{NO}_{2}$ are effectively activated on account of the existence of $\mathrm{Ru}-\mathrm{Ru}$ and $\mathrm{Ru}-\mathrm{Ni}$ interface sites, respectively, corresponding to the formation of 4-NE and 4-AE over $2 w t . \%$ RuNi catalyst.

The potential conversion paths of 4-NS over $\mathrm{Ni}$ (111) and RuNi SAA (111), including the hydrogenation of $\mathrm{C}=\mathrm{C}$ group and cleavage of $\mathrm{N}-\mathrm{O}$ bond were investigated by DFT calculations, so as to further reveal the decisive role of $\mathrm{Ru}-\mathrm{Ni}$ interfacial sites for the target production of 4-AS. For Ni (111) surface (Fig. 6e), the energy barriers of $\mathrm{N}-\mathrm{O}$ scission and the first hydrogenation step in vinyl group are 0.78 and $0.69 \mathrm{eV}$, respectively, demonstrating that 4-NS molecule preferentially undergoes $\mathrm{C}=\mathrm{C}$ hydrogenation over monometallic Ni surface. In contrast, the energy barrier of $\mathrm{N}-\mathrm{O}$ dissociation is merely $0.47 \mathrm{eV}$ over RuNi SAA (111), much lower than that of $\mathrm{C}=\mathrm{C}$ bond hydrogenation (0.72 eV) (Fig. 6f). This unambiguously confirms that the Ru-Ni interface sites effectively reduce the energy barrier of $\mathrm{N}-\mathrm{O}$ scission in nitro group, resulting in the thermodynamically preferential reduction of nitro than $\mathrm{C}=\mathrm{C}$ group on the surface of RuNi SAA, which is in accord with the consequence of experiments.

The reaction mechanism and computational energy profile (Fig. 7) of 4-NS hydrogenation on RuNi SAA were studied based on DFT calculations, and the detailed adsorption configurations for elementary steps were displayed in Supplementary Fig. 31. To optimize computational procedure, the formation of water molecule was excluded from the slab model calculations ${ }^{9,17}$. As shown in Fig. 7, firstly, the 4-NS molecule experiences parallel absorption on RuNi SAA with the two $\mathrm{O}$ atoms in nitro group bond to $\mathrm{Ru}-\mathrm{Ni}$ interface sites (S0; step I). Subsequently, the $\mathrm{N}-\mathrm{O}$ bond connecting with Ru site undergoes breakage, accompanied with the generation of nitroso intermediate $\left(\mathrm{C}_{8} \mathrm{H}_{7} \mathrm{NO}^{*}\right)$ on $\mathrm{Ru}-\mathrm{Ni}$ interfacial sites and $\mathrm{O}$ * on Ni hollow site (S0 $\rightarrow$ S1 via TS1; energy barrier: $0.47 \mathrm{eV}$; step II). The hydrogenation energy barriers of $\mathrm{C}_{8} \mathrm{H}_{7} \mathrm{NO}$ * intermediate (Supplementary Fig. 32, 33) indicate that the active $\mathrm{H}$ atoms from $\mathrm{Ru}-\mathrm{Ni}$ hollow sites preferentially attack $\mathrm{O}$ atom (energy barrier: $0.76 \mathrm{eV}$ ) rather than $\mathrm{N}$ atom (energy barrier: $1.03 \mathrm{eV}$ ), giving rise to $\mathrm{C}_{8} \mathrm{H}_{7} \mathrm{NOH}^{\star}\left(\mathrm{S} 2 \rightarrow \mathrm{S} 4\right.$; step III). Afterwards, the $\mathrm{N}$ atom in $\mathrm{C}_{8} \mathrm{H}_{7} \mathrm{NOH}^{*}$ is hydrogenated to produce $\mathrm{C}_{8} \mathrm{H}_{7} \mathrm{NHOH}^{*}$ after overcoming a barrier of $1.05 \mathrm{eV}$ (S4 $\rightarrow$ S6; step IV), which acts as the rate-determining step of the whole reaction. The $\mathrm{N}-\mathrm{OH}$ bond in $\mathrm{C}_{8} \mathrm{H}_{7} \mathrm{NHOH}^{*}$ further experiences scission on $\mathrm{Ru}-\mathrm{Ni}$ interface sites ( $\mathrm{S} 6 \rightarrow \mathrm{S} 7$; energy barrier: $0.43 \mathrm{eV}$; step $\mathrm{V}$ ), followed by the hydrogenation of $\mathrm{N}$ atom on $\mathrm{Ru}-\mathrm{Ni}$ hollow sites to yield $\mathrm{C}_{8} \mathrm{H}_{7} \mathrm{NH}_{2}$ * (4-AS) with an energy barrier of $0.68 \mathrm{eV}$ (S8 $\rightarrow$ S10; step VI). Finally, desorption of 4-AS occurs from the RuNi SAA surface and the catalyst recovers to its original state (step VII). This unique interfacial structure between Ru single atom and Ni substrate, accompanied by host- 
dopant synergistic effect in RuNi SAA, leads to the outstanding activity and chemoselectivity for 4-NS hydrogenation.

\section{Conclusions}

In summary, a RuNi SAA catalyst was prepared via galvanic replacement reaction between $\mathrm{RuCl}_{3}$ and $\mathrm{Ni}$ NPs derived from LDHs precursor. The resulting RuNi SAA displays an excellent catalytic performance (4AS yield: >99\%; TOF value: $4293 \mathrm{~h}^{-1}$ ) toward chemoselective hydrogenation of 4-NS, in comparison to monometallic $\mathrm{Ru}, \mathrm{Ni}$ and other previously reported heterogeneous catalysts. A combination characterization including AC-HAADF-STEM, in situ CO-DRIFTS and XAFS confirms that the Ru atoms are anchored onto Ni NPs at single-atom level through Ru-Ni bond, accompanied with electron transfer from $\mathrm{Ni}$ to Ru. In situ XAFS, FT-IR experiments and DFT calculations reveal that Ru-Ni interfacial sites serve as the intrinsic active centers to preferentially activate the $\mathrm{N}-\mathrm{O}$ bond in nitro-group; and the synergistic effect between Ru and adjacent $\mathrm{Ni}$ sites facilitates the activation and hydrogenation of intermediates, accounting for the largely enhanced catalytic performance. This work provides atomiclevel insights into the relationship between bifunctional active sites and catalytic behavior of SAA, which paves an avenue for the rational design of other bicomponent catalysts with desirable selectivity.

\section{Methods}

Chemicals and materials. Analytical reagents used in the experiments were bought from Sigma Aldrich:

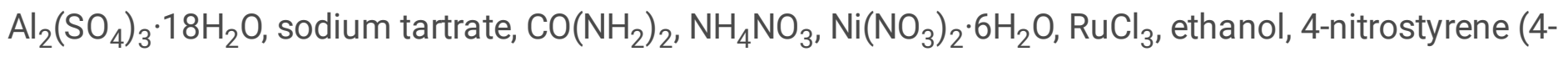
NS), 4-aminostyrene, 4-nitroethylbenzene, 4-aminoethylbenzene, nitrobenzene, styrene. Purified water was adopted in all the experiments.

Synthesis of catalysts. As a precursor, hierarchical NiAl-LDHs was synthesized by in situ growth method reported previously by our group ${ }^{51}$. Afterwards, NiAl-LDHs $(0.3 \mathrm{~g})$ was reduced in a $\mathrm{H}_{2} / \mathrm{N}_{2}(10 / 90, \mathrm{v} / \mathrm{v} ; 35$ $\mathrm{mL} \cdot \mathrm{min}^{-1}$ ) stream at $500{ }^{\circ} \mathrm{C}$ for $4 \mathrm{~h}$ (heating rate: $2^{\circ} \mathrm{C} \cdot \mathrm{min}^{-1}$ ) to prepare amorphous $\mathrm{Al}_{2} \mathrm{O}_{3}$ supported monometallic $\mathrm{Ni}$ sample $\left(\mathrm{Ni} / \mathrm{Al}_{2} \mathrm{O}_{3}\right)$. The supported RuNi bimetallic samples were synthesized by a galvanic replacement method. Typically, the fresh $\mathrm{Ni} / \mathrm{Al}_{2} \mathrm{O}_{3}$ sample $(0.2 \mathrm{~g})$ was dispersed in $30 \mathrm{~mL}$ purified water, followed by slowly adding $\mathrm{RuCl}_{3}$ solution $\left(0.07 \mathrm{mmol} \cdot \mathrm{L}^{-1}\right)$ and stirring vigorously for 60 min under the protection of a $\mathrm{N}_{2}$ atmosphere. The obtained precipitation was centrifugated, washed with purified water, and dried for $24 \mathrm{~h}$ in vacuum oven at $50^{\circ} \mathrm{C}$ to obtain $0.1 \%$ RuNi sample. As a reference, $\mathrm{Ru} / \mathrm{Al}_{2} \mathrm{O}_{3}$ sample was synthesized by a classical deposition precipitation method, with a Ru content of $2.3 w t . \%$. Before catalytic tests, the as-synthesized samples were pre-reduced in a $\mathrm{H}_{2} / \mathrm{N}_{2}$ flow $(10 / 90, \mathrm{v} / \mathrm{v})$ at $300^{\circ} \mathrm{C}$ for $1 \mathrm{~h}$, followed by cooling to the room temperature slowly in $\mathrm{N}_{2}$.

Characterizations. The X-ray diffraction (XRD) experiments were carried out on Bruker DAVINCI D8 ADVANCE diffractometer with a Cu Ka radiation source (40 kV and $40 \mathrm{~mA}$ ). Shimadzu ICPS - 7500 inductively coupled plasma - atomic emission spectrometer (ICP - AES) instrument was used to 
determine the actual element contents of various samples. Scanning electron microscope (SEM) images were displayed by using a Zeiss Supra 55 electron microscope. $\mathrm{N}_{2}$ adsorption-desorption experiments were performed on a Micromeritics ASAP 2020 device, and multipoint Brunauer-Emmett-Teller (BET) method was used to calculate the specific surface area. Transmission electron microscopy (TEM) characterizations were performed on a JEOL JEM-2010 high-resolution transmission electron microscope. JEOL JEM-ARM200F instrument with a spherical aberration corrector and energy-dispersive X-ray spectroscopy (EDS) system were adopted to perform aberration-corrected high angle annular darkfield scanning transmission electron microscopy (AC - HAADF - STEM) and EDS mapping measurements. In situ X-ray absorption fine structure spectroscopy (XAFS) at Ru K-edge and Ni K-edge were measured at the beamline 1W1B and 1W2B of the Beijing Synchrotron Radiation Facility (BSRF), Institute of High Energy Physics (IHEP), Chinese Academy of Sciences (CAS). Hydrogen temperatureprogrammed desorption ( $\mathrm{H}_{2}$-TPD) experiments were carried out on a Micromeritics Autochem II 2920 instrument using a thermal conductivity detector (TCD). In situ DRIFTS and FT-IR experiments were conducted on a Bruker TENSOR II infrared spectrometer equipped with a modified in situ reaction cell and MCT highly-sensitive detector. The detailed characterization methods are described in the Supplementary Information.

Catalytic test. Firstly, substrate (4-NS, $1 \mathrm{mmol})$, solvent (ethanol, $8 \mathrm{ml}$ ) and catalyst $(0.02 \mathrm{~g})$ were carefully added to a $25 \mathrm{~mL}$ stainless-steel autoclave. Subsequently, the reactor was purged completely with 2.0 MPa hydrogen (>99.999\%) for 5 times, followed by pressurized and sealed with $\mathrm{H}_{2}$ to $1.0 \mathrm{MPa}$. The reaction was carried out at $60^{\circ} \mathrm{C}$ with a constant stirring speed of $700 \mathrm{rpm}$. After the reaction is over, the resulting products were identified by GC-MS, and quantitatively analyzed using a Shimadzu GC - 2014C gas chromatograph system outfitted a GSBP - INOWAX capillary column $(30 \mathrm{~m} \times 0.25 \mathrm{~mm} \times 0.25 \mathrm{~mm})$ and an FID detector. The conversion of 4-nitrostyrene and the selectivity of products were determined as follows:

$$
\begin{aligned}
& \text { Conversion }(\backslash \%)=\left(1-\frac{\text { Mole number of } 4 \text {-NS after reaction }}{\text { Initial mole number of } 4 \text {-NS fed }}\right) \times 100 \backslash \% \\
& \text { Selectivity }(\backslash \%)=\frac{\text { Mole number of one product }}{\text { Total mole number of } 4 \text {-NS converted }} \times 100 \backslash \%
\end{aligned}
$$

The turnover frequency (TOF) values were calculated as the molar amount of 4-NS converted per mole of Ru atom per hour $\left(\mathrm{mol}_{4-\mathrm{NS}} \bullet \mathrm{mol}_{\mathrm{Ru}}{ }^{-1} \cdot \mathrm{h}^{-1}\right)$, under a low 4-NS conversion $(\sim 15 \%)$ based on the number of total Ru atoms.

DFT calculations. All the density functional theory (DFT) calculations were performed using the Vienna ab initio simulation package (VASP 5.4.1). The PBE functional with generalized gradient approximation (GGA) was used to describe the electron exchange and correlation term. The projector augmented wave (PAW) method was employed to describe the interaction between atomic cores and electrons. The effect of van der Waals interactions between the substrates and the interface were described by Grimme's DFT- 
D3 method. The energy barriers were calculated by the climbing image nudged elastic band (CI-NEB) method. More detailed computational methods are described in the Supplementary Information.

\section{Data Availability}

The primary data that support the plots within this paper and other finding of this study are available from the corresponding author on reasonable request.

\section{References}

1. Corma, A. \& Serna, P. Chemoselective hydrogenation of nitro compounds with supported gold catalysts. Science 313, $332-334$ (2006).

2. Formenti, D., Ferretti, F., Scharnagl, F. K. \& Beller, M. Reduction of nitro compounds using 3d-nonnoble metal catalysts. Chem. Rev. 119, 2611-2680 (2019).

3. Tan, Y. et al. ZnAl-hydrotalcite-supported $\mathrm{Au}_{25}$ nanoclusters as precatalysts for chemoselective hydrogenation of 3-nitrostyrene. Angew. Chem. Int. Ed. 56, 1-6 (2017).

4. Zhang, L., Zhou, M., Wang, A. \& Zhang, T. Selective hydrogenation over supported metal catalysts: from nanoparticles to single atoms. Chem. Rev. 120, 683-733 (2020).

5. Sun, Q. et al. Zeolite-encaged single-atom rhodium catalysts: highly-efficient hydrogen generation and shape-selective tandem hydrogenation of nitroarenes. Angew. Chem. Int. Ed. 58, 18570-18576 (2019).

6. Tian, S. et al. Dual-atom Pt heterogeneous catalyst with excellent catalytic performances for the selective hydrogenation and epoxidation. Nat. Commun. 12, 3181 (2021).

7. Wang, Y. et al. Chemoselective hydrogenation of nitroaromatics at the nanoscale Iron(III)- $\mathrm{OH}-$ Platinum interface. Angew. Chem. Int. Ed. 59, 12736-12740 (2020).

8. Wei, $\mathrm{H}$. et al. $\mathrm{FeO}_{\mathrm{x}}$-supported platinum single-atom and pseudo-single-atom catalysts for chemoselective hydrogenation of functionalized nitroarenes. Nat. Commun. 5, 5634 (2014).

9. Han, A. et al. Isolating contiguous Pt atoms and forming Pt-Zn intermetallic nanoparticles to regulate selectivity in 4-nitrophenylacetylene hydrogenation. Nat. Commun. 10, 3787 (2019).

10. Wang, C. et al. Insight into single-atom-induced unconventional size dependence over $\mathrm{CeO}_{2}{ }^{-}$ supported Pt catalysts. Chem 6, 1-14 (2020).

11. Feng, Y. et al. On-demand, ultraselective hydrogenation system enabled by precisely modulated $\mathrm{Pd}-$ Cd nanocubes. J. Am. Chem. Soc. 142, 962-972 (2020).

12. Fu, J. et al. Synergistic effects for enhanced catalysis in a dual single-atom catalyst. ACS Catal. 11, 1952-1961 (2021).

13. Liu, L. et al. Determination of the evolution of heterogeneous single metal atoms and nanoclusters under reaction conditions: which are the working catalytic sites? ACS Catal. 9, 10626-10639 (2019). 
14. Yang, N. et al. Amorphous/crystalline hetero-phase Pd nanosheets: one-pot synthesis and highly selective hydrogenation reaction. Adv. Mater. 30, 1803234 (2018).

15. Gao, R. et al. Breaking trade-off between selectivity and activity of nickel-based hydrogenation catalysts by tuning both steric effect and d-band Center. Adv. Sci. 6, 1900054 (2019).

16. Li, M. et al. Origin of the activity of Co-N-C catalysts for chemoselective hydrogenation of nitroarenes. ACS Catal. 11, 3026-3039 (2021).

17. Mao, J. et al. Rational control of the selectivity of a ruthenium catalyst for hydrogenation of 4nitrostyrene by strain regulation. Angew. Chem. Int. Ed. 56, 11971-11975 (2017).

18. Lin, L. et al. A highly CO-tolerant atomically dispersed Pt catalyst for chemoselective hydrogenation. Nat. Nanotechnol. 14, 354-361 (2019).

19. Ye, TN. et al. Stable single platinum atoms trapped in sub-nanometer cavities in $12 \mathrm{CaO} \cdot 7 \mathrm{Al}_{2} \mathrm{O}_{3}$ for chemoselective hydrogenation of nitroarenes. Nat. Commun. 11, 1020 (2020).

20. Han, B. et al. Strong metal-support interactions between Pt single atoms and $\mathrm{TiO}_{2}$. Angew. Chem. Int. Ed. 59, 11824-11829 (2020).

21. Zhang, J. et al. A Pd@zeolite catalyst for nitroarene hydrogenation with high product selectivity by sterically controlled adsorption in the zeolite micropores. Angew. Chem. Int. Ed. 56, 9747-9751 (2017).

22. Trandafir, M. M. et al. Highly efficient ultralow Pd loading supported on MAX phases for chemoselective hydrogenation. ACS Catal. 10, 5899-5908 (2020).

23. $\mathrm{Ma}, \mathrm{Y}$. et al. High-density and thermally stable palladium single-atom catalysts for chemoselective hydrogenations. Angew. Chem. Int. Ed. 59, 21613-21619 (2020).

24. Macino, M. et al. Tuning of catalytic sites in $\mathrm{Pt} / \mathrm{TiO}_{2}$ catalysts for the chemoselective hydrogenation of 3-nitrostyrene. Nat. Catal. 2, 873-881 (2019).

25. Ren, Y. et al. Unraveling the coordination structure-performance relationship in $\mathrm{Pt}_{1} / \mathrm{Fe}_{2} \mathrm{O}_{3}$ single-atom catalyst. Nat. Commun. 10, 4500 (2019).

26. Wang, L. et al. Single-site catalyst promoters accelerate metal-catalyzed nitroarene hydrogenation. Nat. Commun. 9, 1362 (2018).

27. Kyriakou, G. et al. Isolated metal atom geometries as a strategy for selective heterogeneous hydrogenations. Science 335, 1209-1212 (2012).

28. Greiner, M. T. et al. Free-atom-like $d$ states in single-atom alloy catalysts. Nat. Chem. 10, 10081015 (2018).

29. Sun, G. et al. Breaking the scaling relationship via thermally stable Pt/Cu single atom alloys for catalytic dehydrogenation. Nat. Commun. 9, 4454 (2018).

30. Hannagan, R. T., Giannakakis, G., Flytzani-Stephanopoulos, M. \& Sykes, E. C. H. Single-atom alloy catalysis. Chem. Rev. 120, 12044-12088 (2020).

31. Spivey, T. D. \& Holewinski, A. Selective interactions between free-atom-like dstates in single-atom alloy catalysts and near-frontier molecular orbitals. J. Am. Chem. Soc. 143, 11897-11902 (2021). 
32. Liu, K., Qin, R. \& Zheng, N. Insights into the interfacial effects in heterogeneous metal nanocatalysts toward selective hydrogenation. J. Am. Chem. Soc. 143, 4483-4499 (2021).

33. Ouyang, M. et al. Directing reaction pathways via in situ control of active site geometries in $\mathrm{PdAu}$ single-atom alloy catalysts. Nat. Commun. 12, 1549 (2021).

34. Zhang, T., Walsh, A. G., Yu, J. \& Zhang, P. Single-atom alloy catalysts: structural analysis, electronic properties and catalytic activities. Chem. Soc. Rev. 50, 569-588 (2021).

35. Wang, $\mathrm{H}$. et al. Quasi $\mathrm{Pd}_{1} \mathrm{Ni}$ single-atom surface alloy catalyst enables hydrogenation of nitriles to secondary amines. Nat. Commun. 10, 4998 (2019).

36. Peng, Y. et al. Pt single atoms embedded in the surface of Ni nanocrystals as highly active catalysts for selective hydrogenation of nitro compounds. Nano Lett. 18, 3785-3791 (2018).

37. Zhang, X. et al. Platinum-copper single atom alloy catalysts with high performance towards glycerol hydrogenolysis. Nat. Commun. 10, 5812 (2019).

38. Jiang, L. et al. Facet engineering accelerates spillover hydrogenation on highly diluted metal nanocatalysts. Nat. Nanotechnol. 15, 848-853 (2020).

39. Chin, S. Y., Williams, C. T. \& Amiridis, M. D. FTIR studies of $\mathrm{CO}$ adsorption on $\mathrm{Al}_{2} \mathrm{O}_{3}$ - and $\mathrm{SiO}_{2}$ supported Ru catalysts. J. Phys. Chem. B 110, 871-882 (2006).

40. Loveless, B. T., Buda, C., Neurock, M. \& Iglesia, E. CO chemisorption and dissociation at high coverages during CO hydrogenation on Ru catalysts. J. Am. Chem. Soc. 135, 6107-6121 (2013).

41. Layman, K. A. \& Bussell, M. E. Infrared spectroscopic investigation of $\mathrm{CO}$ adsorption on silicasupported nickel phosphide catalysts. J. Phys. Chem. B 108, 10930-10941 (2004).

42. Lee, Y. \& Oyama, S. T. Bifunctional nature of a $\mathrm{SiO}_{2}$-supported $\mathrm{Ni}_{2} \mathrm{P}$ catalyst for hydrotreating: EXAFS and FTIR studies. J. Catal. 239, 376-389 (2006).

43. Wang, Y. et al. Catalytic production of alanine from waste glycerol. Angew. Chem. Int. Ed. 59, 22892293 (2020).

44. Mori, K., Miyawaki, K. \& Yamashita, H. Ru and Ru-Ni nanoparticles on $\mathrm{TiO}_{2}$ support as extremely active catalysts for hydrogen production from ammonia-borane. ACS Catal. 6, 3128-3135 (2016).

45. Meng, G. et al. $\mathrm{Ru}_{1} \mathrm{Co}_{\mathrm{n}}$ single-atom alloy for enhancing Fischer-Tropsch synthesis. ACS Catal. 11, 1886-1896 (2021).

46. Boronat, M. et al. A molecular mechanism for the chemoselective hydrogenation of substituted nitroaromatics with nanoparticles of gold on $\mathrm{TiO}_{2}$ catalysts: a cooperative effect between gold and the support. J. Am. Chem. Soc. 129, 16230-16237 (2007).

47. Shimizu, K. et al. Chemoselective hydrogenation of nitroaromatics by supported gold catalysts: mechanistic reasons of size- and support-dependent activity and selectivity. J. Phys. Chem. C113, 17803-17810 (2009).

48. Zhang, Q. et al. Highly efficient hydrogenation of nitrobenzene to aniline over $\mathrm{Pt} / \mathrm{CeO}_{2}$ catalysts: the shape effect of the support and key role of additional $\mathrm{Ce}^{3+}$ sites. ACS Catal. 10, 10350-10363 (2020). 
49. Meijers, S. \& Ponec, V. An FTIR spectroscopic study of the selective oxidation of nitrosobenzene to nitrobenzene by metal oxides. J. Catal. 160, 1-9 (1996).

50. Combita, D., Concepción, P. \& Corma, A. Gold catalysts for the synthesis of aromatic azocompounds from nitroaromatics in one step. J. Catal. 311, 339-349 (2014).

51 . He, S. et al. A surface defect-promoted Ni nanocatalyst with simultaneously enhanced activity and stability. Chem. Mater. 25, 1040-1046 (2013).

\section{Declarations}

\section{Acknowledgments}

This work was supported by the National Natural Science Foundation of China (21871021 and 21521005), the National Key Research and Development Program (Grant No. 2017YFA0206804), the Beijing Natural Science Foundation (2212012), the Fundamental Research Funds for the Central Universities (XK1802-6 and XK1803-05), and China Postdoctoral Science Foundation (Grant No. 2019M660412). The authors are thankful for the support of the BSRF (Beijing Synchrotron Radiation Facility) during the XAFS measurements at the beamline of 1W1B and 1W2B.

\section{Author contributions}

M.W., Y.Y., and W.L. conceived the idea and designed research. X.Z., H.F. and P.Y. performed the DFT calculations; W.L. synthesized the catalysts and conducted the characterizations and reaction tests; B.Z., S.H. and Y.N. conducted the STEM analyses. L.W. helped the XAFS analysis. All the authors analyzed data and wrote the paper.

\section{Competing interests}

The authors declare no competing interests.

\section{Additional information}

Supplementary information is available for this paper at https://doi.org.

Reprints and permissions information is available at www.nature.com/reprints.

Correspondence and requests for materials should be addressed to M.W. 
Publisher's note: Springer Nature remains neutral with regard to jurisdictional claims in published maps and institutional affiliations.

\section{Figures}
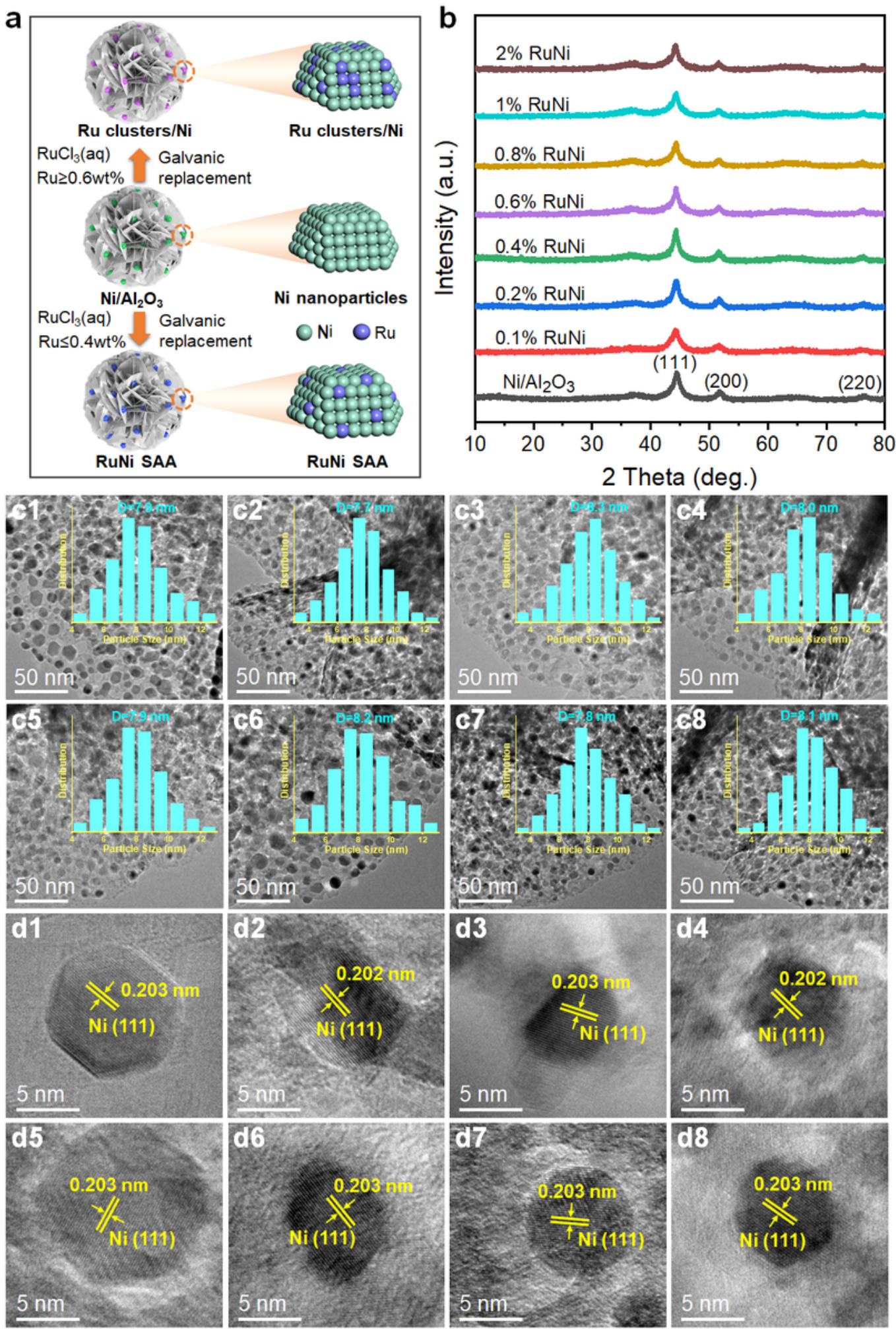

Figure 1 
Preparation route, structure and morphology characterizations of RuNi bimetallic samples. a Schematic illustration for the synthesis route of RuNi/Al2O3 samples; $b$ XRD patterns of Ni/Al2O3 and various RuNi/Al203 samples. c1-c8 TEM images with corresponding particle size distribution and d1-d8 HRTEM lattice fringe images of monometallic Ni, $0.1 \mathrm{wt} . \%, 0.2 \mathrm{wt} . \%, 0.4 \mathrm{wt} . \%, 0.6 \mathrm{wt} . \%, 0.8 \mathrm{wt} . \%, 1 \mathrm{wt} . \%$ and 2 wt.\% RuNi, respectively.

a

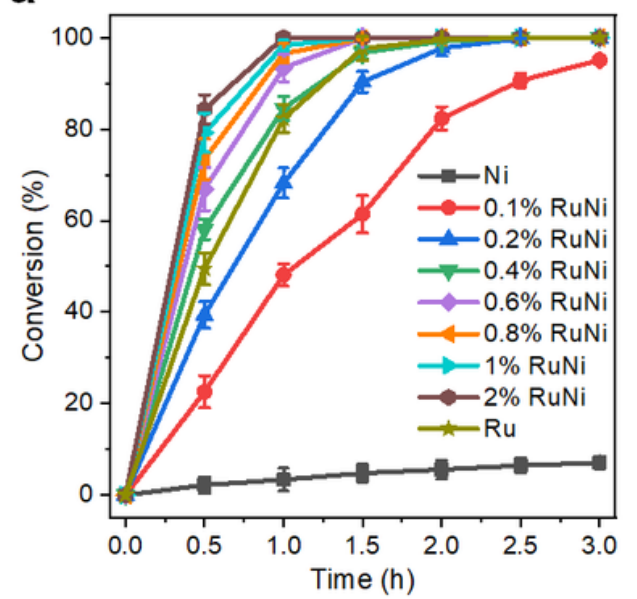

d

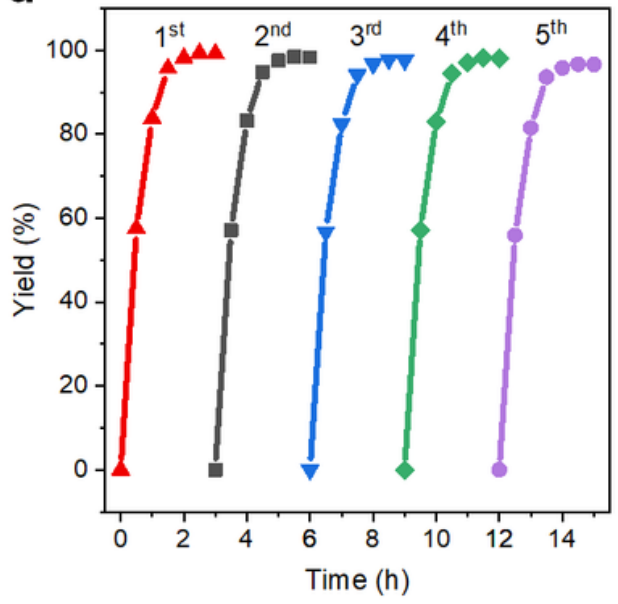

b

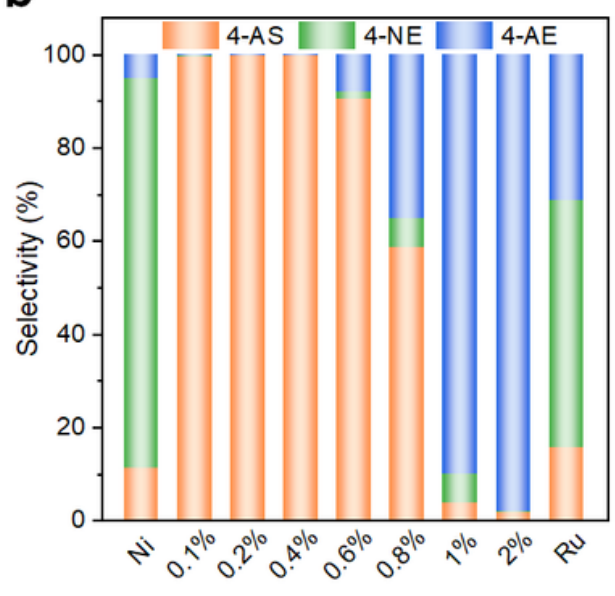

e

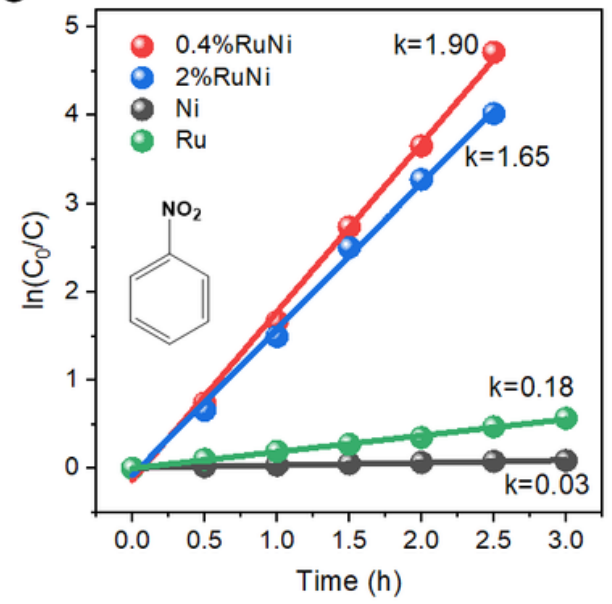

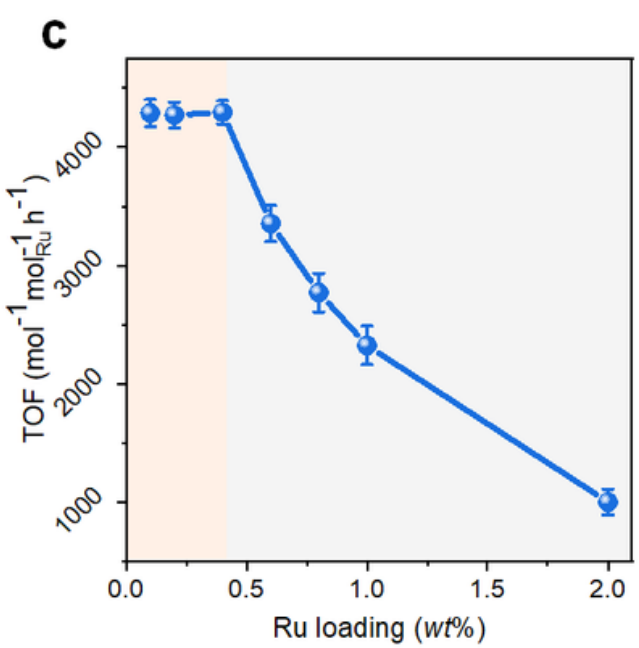

f

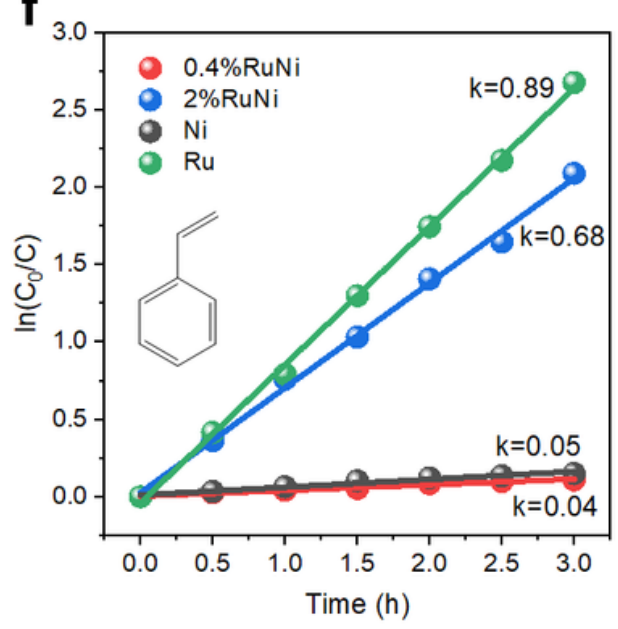

Figure 2

Catalytic performances of various samples toward nitroarenes hydrogenation. a Catalytic conversion of 4-nitrostyrene hydrogenation and b product distribution in the presence of monometallic $\mathrm{Ni}$, Ru and RuNi catalysts with various Ru loading (0.1-2 wt.\%); c Turnover frequency (TOF) over RuNi catalysts as a function of per mole Ru under the catalytic dynamic range. d Reusability tests of 0.4 wt.\% RuNi catalyst within five successive catalytic cycles. In (CO/C) based on e nitrobenzene and f styrene vs. reaction time for the hydrogenation reaction of nitrobenzene and styrene mixture (1:1). Reaction conditions: $1 \mathrm{mmol}$ of reactant; $8 \mathrm{ml}$ of solvent (ethanol); $0.02 \mathrm{~g}$ of catalyst; $1 \mathrm{Mpa}$ of $\mathrm{H} 2,60^{\circ} \mathrm{C}, 3 \mathrm{~h}$. 

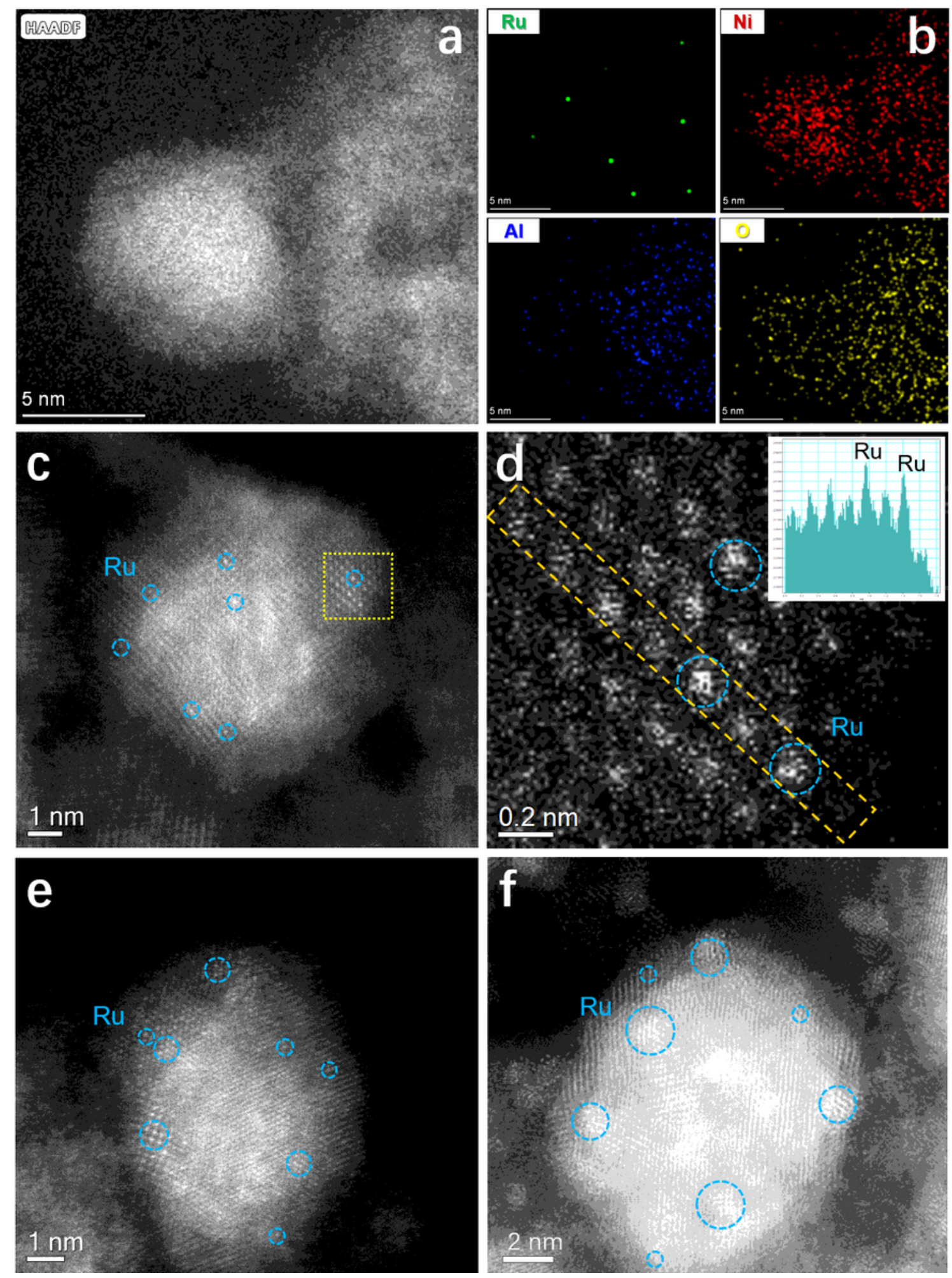

\section{Figure 3}

Electron micrology studies on RuNi catalysts. a HAADF-STEM image, b corresponding EDS mapping images, $c$ high resolution AC-HAADF-STEM image, and e enlarged STEM image and corresponding intensity profile of $0.4 \mathrm{wt} . \%$ RuNi sample. e, f AC-HAADF-STEM images of the $0.6 \mathrm{wt} . \%$ RuNi and $2 \mathrm{wt} . \%$ RuNi samples, respectively. 

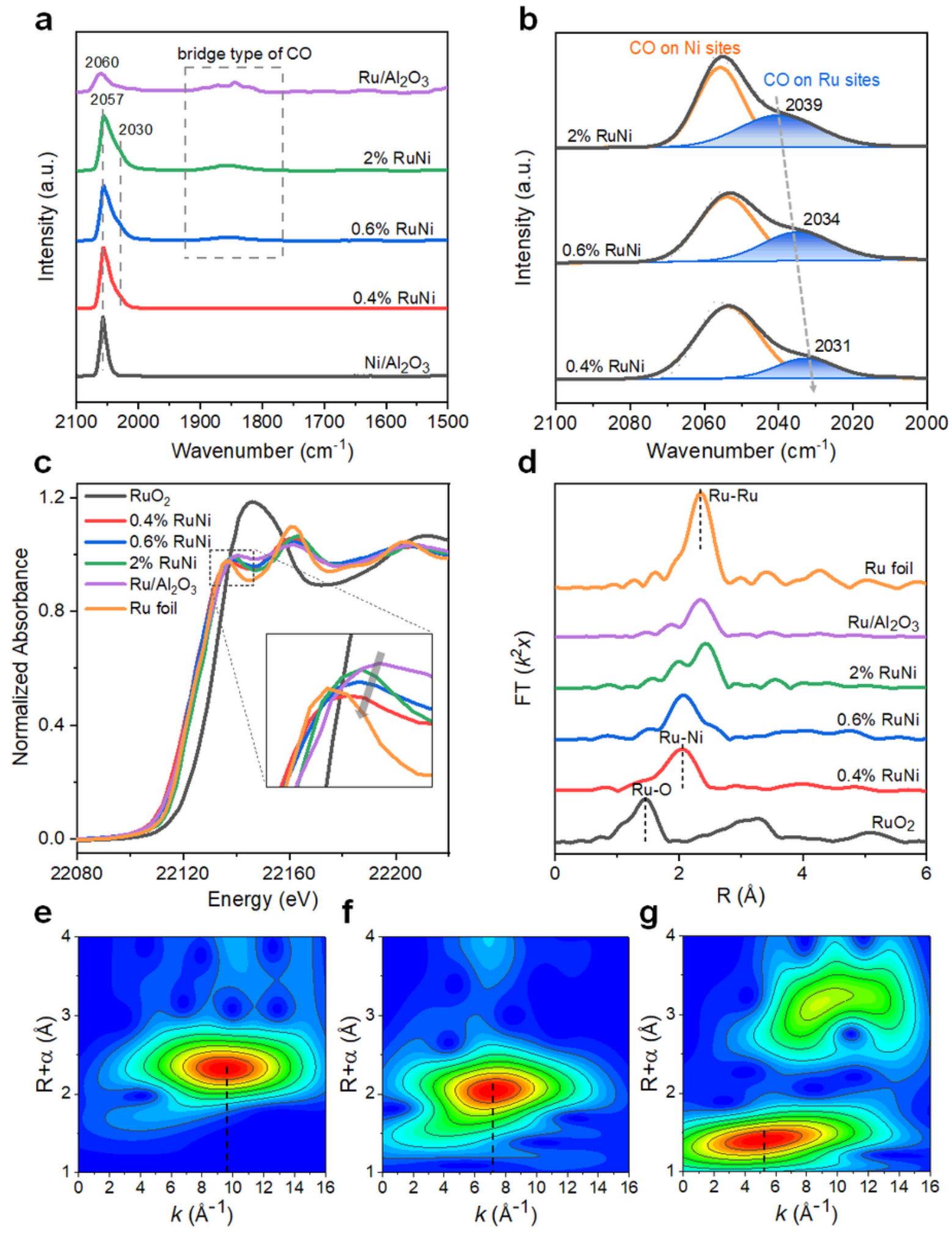

\section{Figure 4}

Fine-structure characterizations of RuNi catalysts. a In situ CO-DRIFTS spectra of Ni/Al203, Ru/Al2O3, and 0.4 wt.\%, 0.6 wt.\%, 2 wt.\% RuNi samples, within 2100-1500 cm-1 by flowing He gas for 20 min. b The enlarged and Gaussian fitting spectra with a fixed peak position and FWHM of RuNi/Al2O3 samples. c In situ Ru K-edge XANES spectra and d EXAFS Fourier-transform spectra of various samples. k2-weighted 
wavelet transforms for the Ru K-edge XAFS signals of e Ru foil, f 0.4 wt.\% RuNi and g RuO2 sample based on Morlet wavelets.

a
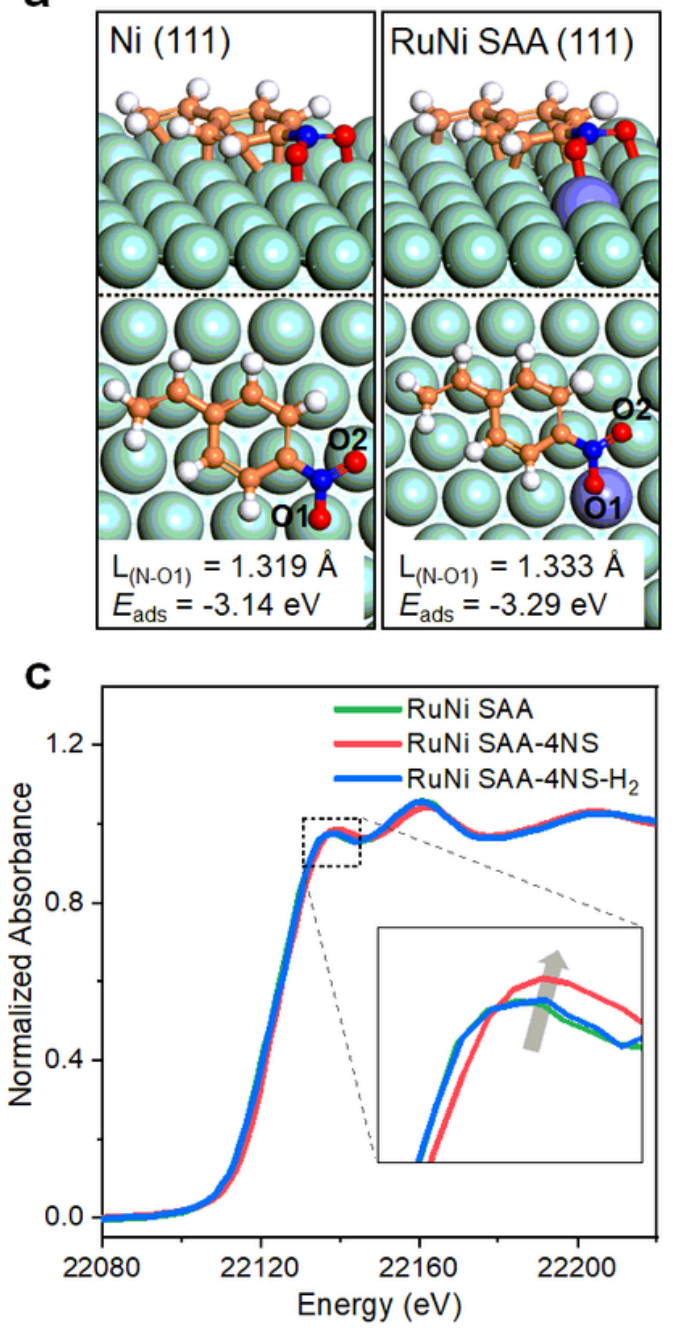

b
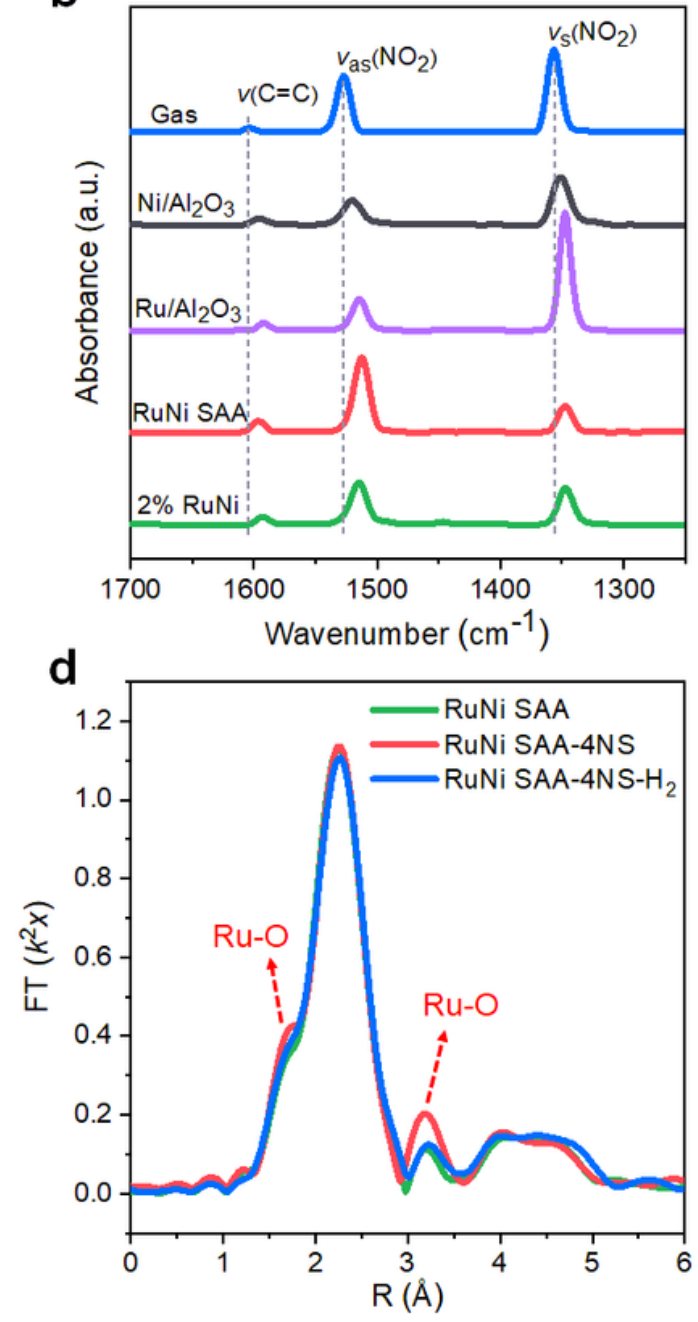

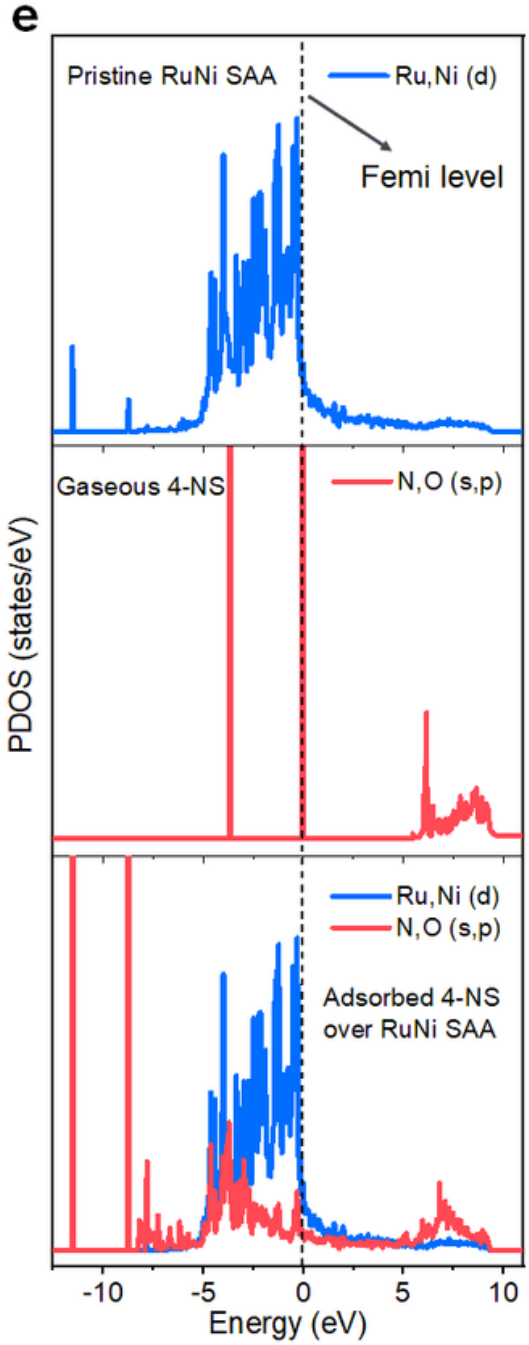

Figure 5

Identification of catalytic active sites. a Adsorption configurations of 4-NS on Ni (111) and RuNi SAA (111) surface, with the labeled bond length of $\mathrm{N}-01$ ( $(\mathrm{N}(\mathrm{N}-\mathrm{O} 1)$ ) and adsorption energies of 4-NS (Eads). Ru, violet; $\mathrm{Ni}$, green; $\mathrm{C}$, orange; $\mathrm{O}$, red; $\mathrm{N}$, blue; $\mathrm{H}$, white. $\mathrm{b}$ In situ FT-IR spectra of gaseous and chemically adsorbed 4-NS on monometallic Ni, Ru, RuNi SAA (0.4 wt.\%) and 2 wt.\% RuNi, respectively. c In situ normalized XANES and d phase correction EXAFS Fourier-transform spectra at Ru K-edge of $0.4 \mathrm{wt} . \%$ RuNi SAA under 4-NS adsorption (RuNi SAA-4NS), and hydrogenation reaction stages (RuNi SAA-4NSH2). e Projected density of states (PDOS) for pristine RuNi SAA (111) surface, N-O1 in gaseous 4-NS, and adsorbed 4-NS over RuNi SAA (111). 

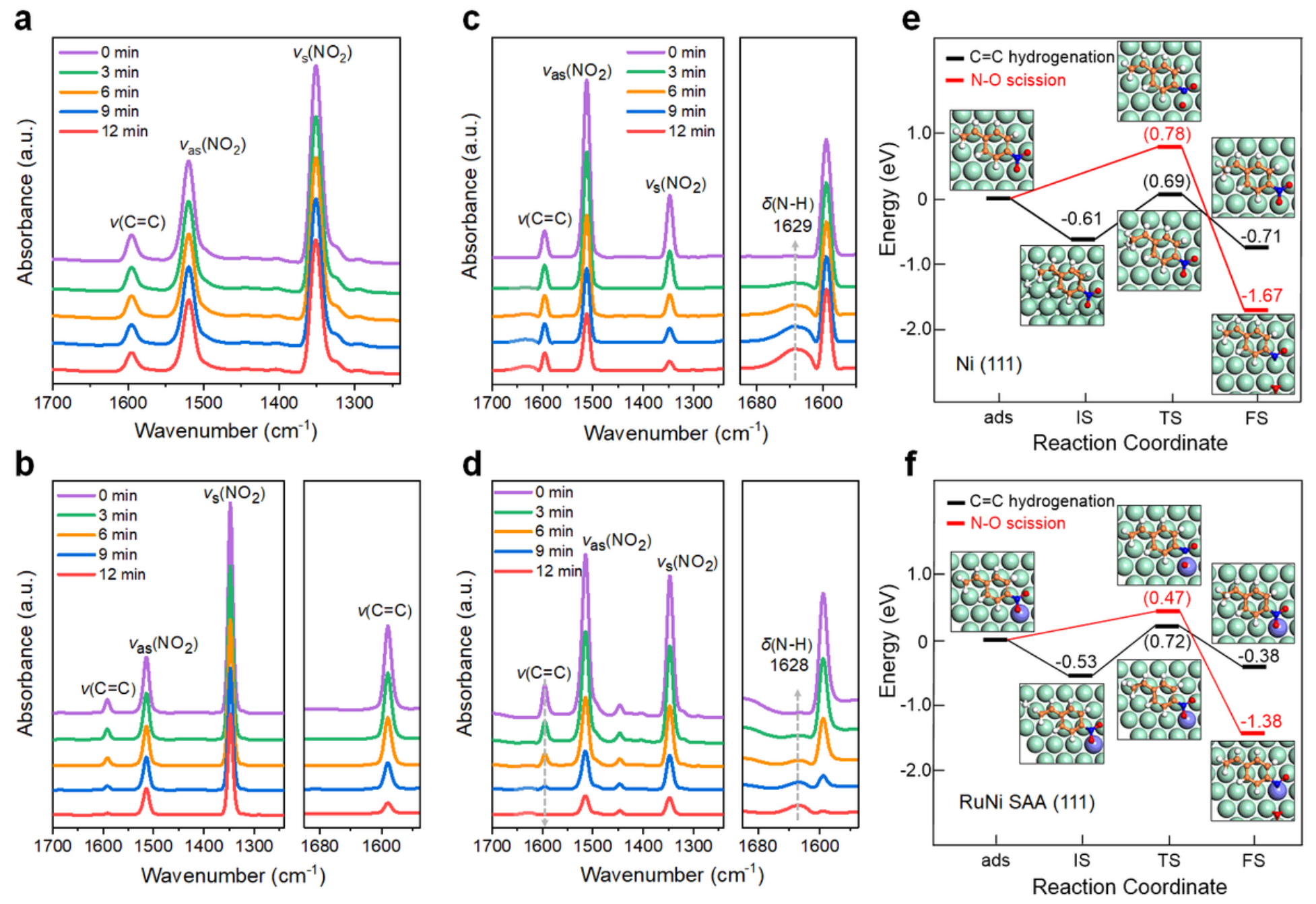

Figure 6

Investigations on reaction paths of 4-NS hydrogenation. In situ FT-IR spectra of 4-NS hydrogenation in the presence of a monometallic Ni, b monometallic Ru, c 0.4 wt.\% RuNi SAA and d 2 wt.\% RuNi, recorded within $1700-1240 \mathrm{~cm}-1$ by flowing $\mathrm{H} 2$ as a reaction gas after $0,3,6,9$ and $12 \mathrm{~min}$, respectively. Potential energy profiles and corresponding optimized structures for $\mathrm{C}=\mathrm{C}$ hydrogenation and $\mathrm{N}-\mathrm{O}$ scission in 4-NS over e Ni (111), and f RuNi SAA (111) surface. Ru, violet; Ni, green; C, orange; O, red; N, blue; $\mathrm{H}$, white. 


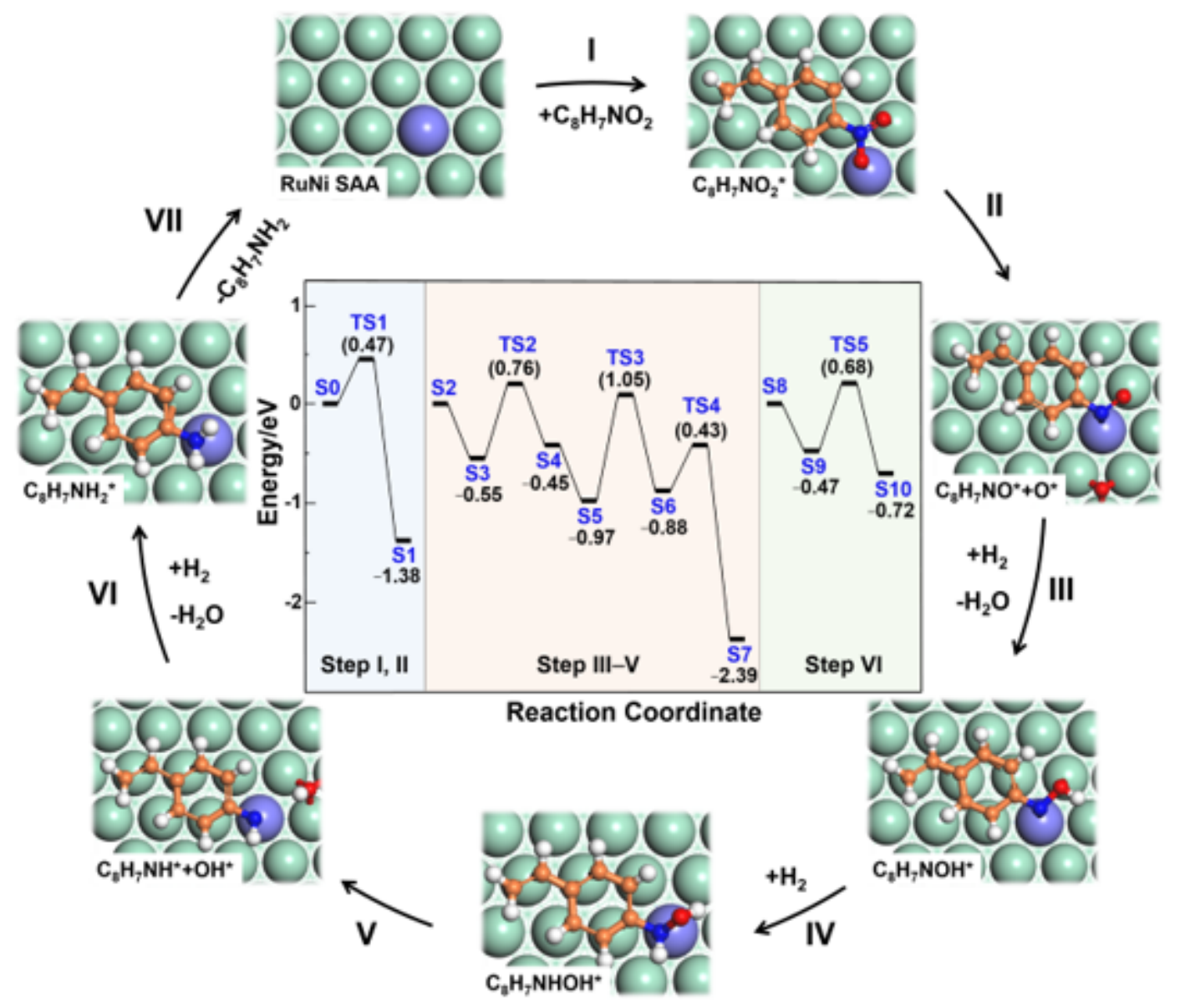

Figure 7

Reaction mechanism of 4-NS hydrogenation to 4-AS over RuNi SAA. A schematic illustration for the reaction mechanism of 4-NS hydrogenation to 4-AS on the surface of RuNi SAA. Ru, violet; Ni, green; C, orange; $\mathrm{O}$, red; $\mathrm{N}$, blue; $\mathrm{H}$, white. The inset shows potential energy profiles for 4-NS hydrogenation on RuNi SAA (111) surface based on DFT calculations. 'TS' denotes a transition state. The numbers in parentheses stand for the energy barriers of the elementary step and the other numbers represent the adsorption energies of corresponding intermediates.

\section{Supplementary Files}

This is a list of supplementary files associated with this preprint. Click to download.

- TableofContents.png

- Supplementaryinformation.docx 